Rian Andriani, Erlangga Brahmanto dan Beatrix C. C. Simamora Purba: Value Tari SigaleGale Dalam Meningkatkan Wisata Budaya Di Desa Tomok Kabupaten Samosir

\title{
VALUE TARI SIGALE-GALE DALAM MENINGKATKAN WISATA BUDAYA DI DESA TOMOK KABUPATEN SAMOSIR
}

\author{
Rian Andriani ${ }^{(1)}$, Erlangga Brahmanto ${ }^{(2)}$, Beatrix C. C. Simamora Purba ${ }^{(3)}$ \\ (1) AKPAR BSI Bandung (2) Universitas Bina Sarana Informatika \\ (3) STP ARS Internasional

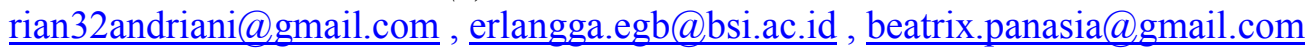

\begin{abstract}
ABSTRAK
Tari Sigale-gale merupakan tarian sebuah patung kayu yang digerakkan oleh manusia dengan diiringi alunan musik khas Batak. Tari Sigale-gale sempat menjadi icon pada acara Festival Danau Toba tahun 2013. Adanya pergeseran nilai tari Sigale-gale dikarenakan perubahan cara penyuguhan tari Sigale-gale tersebut dengan memutar kaset yang sebelumnya selalu diiringi alunan alat-alat musik khas Batak. Tujuan penelitian ini untuk mengetahui esensi dan nilai yang terkandung dari tari Sigale-gale dalam meningkatkan wisata budaya di Desa Tomok Kabupaten Samosir. Penelitian ini menggunakan metode kualitatif bersifat deskriptif. Hasil penelitian ini menyatakan bahwa Tari Sigale-gale merupakan suatu pertunjukan yang menceritakan tradisi suku Batak Toba pada zaman dahulu. Prosesinya sejak dahulu hingga kini tidak mengalami perubahan namun cara menampilkannya yang berubah. Kesimpulan dari penelitian ini adalah bahwa nilai tari Sigale-gale perlu dipertahankan dengan mengembalikan cara menampilkan pertunjukannya seperti sedia kala dan menghadirkan penari yang handal dalam menarik wisatawan untuk manortor (menari).
\end{abstract}

Kata Kunci: Value, Tari Sigale-gale, Wisata Budaya

\section{VALUE OF SIGALE-GALE DANCE TO INCREASE CULTURE TOURISM IN TOMOK VILLAGE, SAMOSIR DISTRICT}

\begin{abstract}
Tari Sigale-gale is a dance of a wooden statue that is driven by humans accompanied by typical Batak music. Sigale-gale dance had become an icon in the 2013 Lake Toba Festival. The shift in the value of Sigale-gale dance was due to changes in the way the Sigale-gale dance was presented by playing tapes which were always accompanied by strains of Batak musical instruments. The purpose of this study was to determine the essence and value contained in Sigale-gale dance in enhancing cultural tourism in Tomok Village, Samosir Regency. This study uses descriptive qualitative methods. The results of this study state that Sigale-gale Dance is a performance that tells the traditions of the Batak Toba tribe in ancient times. The procession has not changed until now but the way it is displayed changes. The conclusion of this study is that the value of Sigale-gale dance needs to be maintained by returning the way to show the show as usual and presenting dancers who are reliable in attracting tourists to dance.
\end{abstract}

Keywords: Value, Sigale-Gale Dance, Culture Tourism 


\section{PENDAHULUAN}

Sumatera Utara merupakan provinsi yang beribukotakan Medan, dijuluki sebagai Kota Melayu Deli dan menjadi kota terbesar ketiga di Indonesia setelah Kota Jakarta dan Kota Surabaya (Pinem Mbina, 2009:57). Destinasi wisata yang populer di Kota Medan yaitu destinasi wisata sejarah dan destinasi wisata budaya. Letak destinasi tersebut terbagi atas 3 ciri kebudayaan yang berbeda-beda yaitu kawasan Alun-alun jalan Merdeka yang khas dengan bangunanbangunan tua ala Eropa yang bersejarah yang dibangun dengan Art Deco dan gaya arsitektur Renaissance, kawasan Maimun yang dikenal sebagai pusat budaya Melayu dan kawasan Kampung Kesawan yang memiliki ciri kebudayaan orang Tionghoa yang berasal dari Tiongkok dan Malaka (Ginting, 2016:195).

Kebudayaan yang beragam merupakan potensi destinasi wisata untuk menarik perhatian wisatawan, sehingga kepariwisataan di Sumatera Utara dapat berkembang pesat (Dinas Pariwisata Kabupaten Samosir, 2018). Perkembangan pariwisata dapat dilihat dari seberapa banyak jumlah wisatawan yang berkunjung ke Provinsi Sumatera Utara untuk bersantai, menghabiskan waktu luangnya (masa liburnya) dan loyal dalam mengkonsumsi produk-produk wisata yang ditawarkan (Sagala, 2017:3). Untuk mengetahui jumlah wisatawan yang berkunjung ke Provinsi Sumatera Utara, maka disajikan tabel I.1 sebagai berikut:

Tabel I.1.

Wisatawan Mancanegara yang Datang ke Provinsi Sumatera Utara Pada Tahun 2011 - 2015

\begin{tabular}{ccccc}
\hline Tahun & $\begin{array}{c}\text { Bandar Udara } \\
\text { Polonia }\end{array}$ & $\begin{array}{c}\text { Pelabuhan Laut } \\
\text { Belawan }\end{array}$ & $\begin{array}{c}\text { Pelabuhan Laut } \\
\text { Tanjungbalai Asahan }\end{array}$ & Jumlah \\
\hline 2011 & 192650 & 18975 & 11501 & 223126 \\
2012 & 205845 & 22132 & 13856 & 241833 \\
2013 & 225550 & 22631 & 11118 & 259299 \\
2014 & 234724 & 24769 & 11344 & 270837 \\
2015 & 197818 & 20916 & 10554 & 229288 \\
\hline
\end{tabular}

Sumber: BPS Provinsi Sumatera Utara (2018)

Berdasarkan tabel I.1 dapat disimpulkan bahwa jumlah kunjungan wisatawan mancanegara yang datang ke Provinsi Sumatera Utara sejak tahun 2011 sampai tahun 2014 selalu mengalami peningkatan. Namun dari tahun 2014 ke tahun 2015 jumlah wisatawan mancanegara yang datang ke Sumatera Utara mengalami penurunan dalam jumlah besar. Penurunan jumlah kunjungan merupakan hal yang harus diperhatikan dan dapat disebabkan oleh banyak faktor (Dinas Pariwisata Kabupaten Samosir, 2018). Apabila penurunan jumlah kunjungan disebabkan oleh kurangnya inovasi pada pertunjukan di suatu destinasi wisata maka perlu membuat terobosan baru agar para wisatawan datang kembali (Renava dkk, 2018).
Inovasi dapat dilahirkan dari keberagaman budaya yang ada di Provinsi Sumatera Utara khususnya Kota Medan. Kota dan desa dapat menjadi daya tarik wisata favorit bagi para wisatawan lokal maupun wisatawan mancanegara apabila dikelola dengan serius oleh pemerintah dan masyarakat setempat (Amanah et al., 2018:372). Daya tarik wisata itu sendiri diklasifikasikan menjadi 2 jenis yaitu, daya tarik wisata alam yang sangat memesona dan daya tarik wisata buatan yang memukau setiap wisatawan nusantara maupun wisatawan mancanegara.

Perpaduan daya tarik wisata alam dan daya tarik wisata buatan mampu membuat Provinsi Sumatera Utara menjadi daerah tujuan wisata unggulan Indonesia di masa 
Rian Andriani, Erlangga Brahmanto dan Beatrix C. C. Simamora Purba: Value Tari SigaleGale Dalam Meningkatkan Wisata Budaya Di Desa Tomok Kabupaten Samosir

yang akan datang (Dinas Pariwisata tarik wisata yang ada di Provinsi Sumatera Kabupaten Samosir, 2018). Jenis-jenis daya Utara. Dapat dilihat pada Tabel I.2.

Tabel I.2.

Jenis-Jenis Daya Tarik Wisata Provinsi Sumatera Utara

\begin{tabular}{|c|c|c|c|}
\hline No & $\begin{array}{c}\text { Jenis } \\
\text { Destinasi }\end{array}$ & Nama Destinasi & Lokasi Destinasi \\
\hline 1 & & Air Terjun Sipiso-Piso & Kab. Karo \\
\hline 2 & & Bukit Gundaling & Kab. Karo \\
\hline 3 & & Bukit Lawang & Kab. Langkat \\
\hline 4 & & Danau Toba & Kab. Toba Samosir \\
\hline 5 & & Gunung Sibayak & Kab. Karo \\
\hline 6 & & Gunung Sinabung & Kab. Karo \\
\hline 7 & Wisata Alam & Pantai Pandan & Kab. Tapanuli Tengah \\
\hline 8 & & Pulau Nias & Kab. Nias \\
\hline 9 & & Pulau Samosir & Kab. Samosir \\
\hline 10 & & Sungai Wampu & Kab. Langkat \\
\hline 11 & & $\begin{array}{c}\text { Taman Nasional Gunung } \\
\text { Leuser }\end{array}$ & Kab. Langkat \\
\hline 12 & & Teluk Lagundri & Kab. Nias \\
\hline 13 & & Ambarita & Kab. Samosir \\
\hline 14 & & Brastagi & Kab. Karo \\
\hline 15 & & Desa Lingga & Kab. Karo \\
\hline 16 & & Istana Maimun & Kota Medan \\
\hline 17 & & $\begin{array}{c}\text { Kampung Keling/Kampung } \\
\text { Madras }\end{array}$ & Kota Medan \\
\hline 18 & & $\begin{array}{l}\text { Makam Pahlawan } \\
\text { Sisingamangaraja }\end{array}$ & Kab. Toba Samosir \\
\hline 19 & Wisata & Mesjid Raya Medan & Kota Medan \\
\hline 20 & Buatan & Museum Balige & Kab. Toba Samosir \\
\hline 21 & & Museum Bukit Barisan & Kota Medan \\
\hline 22 & & Pangururan & Kab. Samosir \\
\hline 23 & & Pura Sri Mariamman & Kota Medan \\
\hline 24 & & Simanindo & Kab. Samosir \\
\hline 25 & & Taman Buaya Asam Kumbang & Kota Medan \\
\hline 26 & & Tomok & Kab. Samosir \\
\hline 27 & & Tuk-Tuk & Kab. Samosir \\
\hline 28 & & Vihara Gunung Timur & Kota Medan \\
\hline
\end{tabular}

Berdasarkan tabel I.2 dapat disimpulkan bahwa Provinsi Sumatera Utara sangat kaya akan potensi-potensi daya tarik wisata. Potensi wisata dapat menjadi media untuk memperkenalkan kebudayaan setiap suku yang ada di Sumatera Utara (Dinas Pariwisata Kabupaten Samosir, 2018).

Kebudayaan dapat disampaikan melalui pameran pakaian adat dan alat-alat musik tradisional untuk mengedukasi wisatawan, pertunjukan seni tari yang interaktif serta memiliki daya tarik bersifat menyenangkan dan lain sebagainya (Dinas Pariwisata Kabupaten Samosir, 2018). Berbicara tentang tarian, Provinsi Sumatera Utara memiliki empat belas tarian daerah dari beberapa suku, yaitu sebagai berikut: 
Tabel I.3.

Ragam Tarian di Provinsi Sumatera Utara

\begin{tabular}{ccc}
\hline No & Ragam Tarian & Suku \\
\hline 1 & Tari Fataele & Nias \\
\hline 2 & Tari Maena & Nias \\
\hline 3 & Tari Moyo & Nias \\
\hline 4 & Tari Piso Surit & Batak Karo \\
\hline 5 & Tari Rondang Bulan & Batak Mandailing \\
\hline 6 & Tari Endeng-Endeng & Batak Mandailing \\
\hline 7 & Tari Persembahan & Melayu \\
\hline 8 & Tari Serampang Dua Belas & Melayu \\
\hline 9 & Tari Tak-Tak Garo-Garo & Batak Phakpak \\
\hline 10 & Tari Huda-Huda & Batak Simalungun \\
\hline 11 & Tari Manduda & Batak Simalungun \\
\hline 12 & Tari Tandok & Batak Toba \\
\hline 13 & Tari Tor-Tor & Batak Toba \\
\hline 14 & Tari Sigale-Gale & Batak Toba \\
\hline
\end{tabular}

Sumber: Dinas Pariwisata Kabupaten Samosir (2018)

Tabel 1.3 menjelaskan bahwa di Provinsi Sumatera Utara terdapat 7 suku dengan tarian khas masing-masing. Hanya beberapa tarian yang dikemas menjadi suatu pertunjukan wisata di daerah-daerah dimana tarian tersebut berasal agar kebudayaan tetap lestari dari generasi ke generasi. Untuk menunjang kegiatan wisata di Provinsi Sumatera Utara, Kementerian Pariwisata memfokuskan percepatan pembangunan salah satu destinasi wisata yaitu Danau Toba yang termasuk dalam program 10 destinasi pariwisata prioritas atau yang lebih dikenal dengan istilah 10 Bali baru, yang menjadi program kerja Kementerian Pariwisata sejak tahun 2016 sampai tahun 2019 (Dinas Pariwisata Kab. Samosir, 2018).

Pembangunan Danau Toba bertujuan untuk meningkatkan pendapatan negara khususnya pendapatan daerah. Sejalan dengan apa yang dipaparkan Brahmanto (2014:69) bahwa "dewasa ini guna meningkatkan pendapatan asli daerah, maka tiap daerah berlomba-lomba untuk mencari objek wisata yang berpotensi mendatangkan wisatawan sebanyak banyaknya". Berdasarkan apa yang telah dipaparkan, dapat disimpulkan bahwa Kementerian
Pariwisata melihat potensi wisata yang dimiliki Danau Toba perlu dikembangkan.

Danau Toba tidak sekedar indah tapi juga unik karena terdapat pulau yang turut menjadi bagian dari keindahannya yaitu Pulau Samosir. Wisatawan yang berkunjung ke Danau Toba pada umumnya akan datang mengunjungi Pulau Samosir juga. Kedatangan wisatawan perlu disambut dengan baik untuk menciptakan kesan pertama yang menyenangkan dan memastikan bahwa apa yang dibutuhkan wisatawan telah terpenuhi. Hal yang serupa dipaparkan Hariyanto, dkk (2018:15) bahwa "Kebutuhan berwisata masa kini merupakan hak setiap orang dan telah bergeser menjadi kebutuhan pokok seperti halnya kebutuhan lainnya pangan, sandang dan papan yang harus dipenuhi". Artinya, bahwa dengan memenuhi kebutuhan pokok wisatawan, maka akan mendorong minat wisatawan tersebut untuk berwisata kembali dan menjadi rekomendasi liburan kepada saudara dan kerabatnya untuk berwisata ke Desa Tomok, sehingga berdampak pada jumlah kunjungan dari tahun ke tahun seperti pada tabel I.4 berikut ini: 
Rian Andriani, Erlangga Brahmanto dan Beatrix C. C. Simamora Purba: Value Tari SigaleGale Dalam Meningkatkan Wisata Budaya Di Desa Tomok Kabupaten Samosir

Tabel I.4.

Jumlah Kunjungan Wisatawan ke Pulau Samosir Tahun 2011-2017

\begin{tabular}{ccccccccc}
\hline No & Bulan & $\mathbf{2 0 1 1}$ & $\mathbf{2 0 1 2}$ & $\mathbf{2 0 1 3}$ & $\mathbf{2 0 1 4}$ & $\mathbf{2 0 1 5}$ & $\mathbf{2 0 1 6}$ & $\mathbf{2 0 1 7}$ \\
\hline 1 & Januari & 8.582 & 16.245 & 14.536 & 23.356 & 19.096 & 23.806 & 38.321 \\
\hline 2 & Februari & 8.236 & 6.966 & 8.386 & 7.448 & 8.822 & 11.930 & 10.936 \\
\hline 3 & Maret & 7.873 & 7.690 & 8.467 & 9.727 & 10.776 & 10.552 & 13.362 \\
\hline 4 & April & 10.875 & 9.524 & 9.255 & 10.714 & 11.899 & 11.265 & 26.621 \\
\hline 5 & Mei & 13.538 & 12.895 & 11.067 & 13.778 & 10.448 & 17.435 & 16.230 \\
\hline 6 & Juni & 10.419 & 12.722 & 13.353 & 10.848 & 14.256 & 9.080 & 51.964 \\
\hline 7 & Juli & 9.537 & 9.160 & 14.572 & 20.662 & 25.845 & 42.107 & 20.958 \\
\hline 8 & Agustus & 9.461 & 22.140 & 24.982 & 17.887 & 10.968 & 11.122 & 13.072 \\
\hline 9 & September & 22.137 & 8.945 & 8.160 & 10.281 & 9.291 & 10.807 & 17.193 \\
\hline 10 & Oktober & 9.682 & 10.856 & 10.551 & 12.045 & 9.076 & 6.870 & 16.243 \\
\hline 11 & November & 8.348 & 8.877 & 9.211 & 13.810 & 11.698 & 9.276 & 13.134 \\
\hline 12 & Desember & 13.941 & 18.807 & 17.239 & 24.389 & 33.288 & 26.478 & 40.025 \\
\hline & Jumlah & 132.629 & 144.827 & 149.779 & 174.945 & 175.463 & 190.728 & 278.059 \\
\hline
\end{tabular}

Sumber: Dinas Pariwisata Kabupaten Samosir (2018)

Kesimpulan yang dapat ditarik dari tabel I.4 yaitu, jumlah wisatawan yang berkunjung ke Pulau Samosir sejak tahun 2011 sampai tahun 2017 selalu mengalami peningkatan setiap tahunnya. Dengan demikian dapat dikatakan bahwa Pulau Samosir memiliki daya tarik wisata yang memikat minat wisatawan.

Pulau Samosir terletak di Kabupaten Samosir dan Pangururan sebagai ibu kotanya (Dinas Pariwisata Kabupaten Samosir, 2018). Pulau Samosir merupakan suatu destinasi yang tidak asing lagi di telinga wisatawan nusantara maupun wisatawan mancanegara karena lingkungannya yang asri dan suhu udaranya yang sejuk. Pulau yang terletak di tengah danau Toba menambah daya tarik wisata karena di pulau ini terdapat banyak pedesaan yang mengandalkan sektor pariwisata sebagai tulang punggung pendapatan daerah (Wardani dan Nasution, 2016:3). Tiaptiap pedesaan memiliki daya tarik wisata yang beraneka ragam sehingga setiap langkah wisatawan dari satu desa ke desa lainnya akan menciptakan kesan yang berbeda-beda. Nama-nama desa wisata yang berada di Pulau Samosir yaitu Desa Tuk-Tuk menampilkan proses memahat patung khas batak, Desa Ambarita menampilkan 8 Rumah Bolon (rumah adat batak) dan kursi persidangan peninggalan Raja Siallagan, Desa Simanindo menampilkan upacara Mangalahat Horbo dan warisan bersejarah dari Raja Sidauruk berupa Museum Huta Bolon, Pangururan tempat para pengrajin kain adat Batak yaitu ulos dan Desa Tomok menampilkan makam tua Raja Sidabutar serta tari Sigale-gale (Dinas Pariwisata Kabupaten Samosir, 2018).

Desa Tomok merupakan salah satu destinasi wisata yang sangat mengesankan dan menarik minat wisatawan lokal maupun wisatawan mancanegara untuk berwisata karena terletak di Pulau Samosir yang dikenal sebagai pulau wisata dengan beragam keunikan baik alam, sejarah dan budayanya (Sagala, 2017:3-4). Selain itu, letak Desa Tomok juga sangat strategis karena menjadi pintu masuk utama bagi para wisatawan yang datang dari pelabuhan Parapat maupun pelabuhan Ajibata hendak berwisata ke Pulau Samosir dengan menggunakan kapal kecil maupun kapal Ferry sebagai moda transportasi (Hanan, 2012:801). Wisatawan yang tiba di Desa Tomok akan disuguhkan dengan berbagai pilihan destinasi wisata. Para wisatawan dapat menikmati panorama Danau Toba dari pelabuhan Tomok, mengunjungi makam tua Raja Sidabutar, museum Batak Tomok, makam Raja Sijabat yang berada di atas 
pohon dan menyaksikan pertunjukan tari Sigale-gale yang merupakan destinasi wisata budaya unggulan di Desa Tomok, Kabupaten Samosir (Dinas Pariwisata Kabupaten Samosir, 2018).

Daya tarik wisata yang sering menjadi buah bibir wisatawan yaitu pertunjukan tari Sigale-gale. Pertunjukan patung yang menari dengan iringan musik batak. Patung tersebut terbuat dari kayu dan digerakkan oleh seseorang dari belakangnya dengan menarik tali pengikat, tari Sigale-gale pada umumnya dilakukan untuk upacara pemakaman (terutama pemakaman kaum pria) dan menjadi suatu pertunjukan wisata khas Batak (Suriadi, 2015:98). Tarian Sigale-gale semakin familiar saat dijadikan icon pada acara Festival Danau Toba tahun 2013. Patung Sigale-gale raksasa dibuat dan diarak di danau dari Tomok ke Tuk-Tuk, dengan demikian wisatawan yang melihat patung raksasa tersebut akan mencari tahu informasi tentang tari Sigale-gale, masterpiece Desa Tomok yang harus dijaga dan diperkenalkan kepada wisatawan (Dinas Pariwisata Kabupaten Samosir, 2018).

Memperkenalkan tari Sigale-gale berarti menyebarluaskan nilai-nilai yang ada dalam tarian tersebut. Nilai-nilai yang terdapat dalam pertunjukan tari Sigale-gale yaitu nilai estetis pada gerak tari dan irama musik serta nilai-nilai kebudayaan suku Batak Toba yaitu nilai kekerabatan, nilai religi, nilai hagabeon (memiliki banyak keturunan/beranak cucu), nilai hasangapon (memiliki status sosial yang tinggi), nilai hamoraon (memiliki harta), nilai marsisarian (saling mengerti, menghargai dan membantu), nilai patik dohot uhum (kesungguhan dalam menegakkan keadilan), nilai pengayoman dan nilai konflik (sikap bijaksana dalam menghadapi perbedaan maupun masalah), (Sigalingging, 2013:4).

Nilai-nilai yang tersirat dalam pertunjukan tari Sigale-gale sungguh sangat luhur, pesan moral dan sosial yang terkandung memberikan gambaran tentang pedoman hidup dan cara masyarakat Batak Toba memaknai kehidupannya (Syarifuddin,
2017:10). Nilai-nilai kebaikan yang menginspirasi membentuk karya seni yang indah dan unik, membuat seseorang atau sekelompok orang ingin mengunjungi dan menyaksikan karya tersebut sehingga terciptalah suatu destinasi wisata dalam bentuk pertunjukan (Hariyanto, 2017:35). Maka dapat disimpulkan bahwa kepariwisataan merupakan bagian dari kebudayaan yang mencakup tradisi, kearifan lokal, struktur kehidupan, prosesi ritual dan hasil kerajinan/karya seni yang bertujuan untuk memperkuat jati diri masyarakat, memupuk rasa cinta terhadap kebudayaan dan meningkatkan pertumbuhan ekonomi masyarakat sekitar (Hariyanto, 2016:217).

Kehadiran destinasi wisata Sigale-gale menjadi solusi ekonomi sekaligus solusi pelestarian alam, sumber daya manusia dan pelestarian budaya yang bisa dicapai melalui proses penanaman tata nilai (Brahmanto, 2013:46). Artinya, nilai-nilai yang terkandung dalam tari Sigale-gale memiliki dampak positif, keterkaitan dan memiliki pengaruh terhadap wisata budaya lainnya yang ada di sekeliling desa Tomok, Kabupaten Samosir. Seiring perkembangan zaman banyak kendala yang dihadapi masyarakat dalam melestarikan tari Sigalegale. Tersedianya beberapa pilihan destinasi yang juga mengadopsi tari Sigale-gale (desadesa lain) membuat jumlah wisatawan yang berkunjung ke destinasi tari Sigale-gale berasal mengalami penurunan (Dinas Pariwisata Kab. Samosir, 2018). Berkurangnya wisatawan dikarenakan jarak destinasi satu dengan yang lainnya masih tergolong dekat. Bahkan di Desa Tomok sendiri terdapat 3 tempat yang menampilkan tari Sigale-gale, sehingga penghasilan para penggiat seni tari Sigale-gale di tempat asalnya berkurang drastis membuat para penggiat seni tari Sigale-gale beralih profesi yaitu menjadi petani untuk mencukupi kebutuhan hidupnya (Dinas Pariwisata Kab. Samosir, 2018). Perubahan tersebut turut mengubah tata cara menampilkan tari Sigale-gale. Dulu pertunjukan diiringi alatalat musik tradisional khas batak dan 3 
Rian Andriani, Erlangga Brahmanto dan Beatrix C. C. Simamora Purba: Value Tari SigaleGale Dalam Meningkatkan Wisata Budaya Di Desa Tomok Kabupaten Samosir

pemandu tari bagi wisatawan, sekarang menjadi iringan kaset yang diputar tanpa pemandu tari (Dinas Pariwisata Kab. Samosir, 2018). Perubahan tersebut membuat pertunjukan Sigale-gale menjadi kurang menarik bagi wisatawan yang berkunjun.

Pertunjukan Sigale-gale yang kurang menarik dikarenakan kurang lengkapnya unsur seni dan budaya suku Batak di dalamnya. Seni tari masyarakat Batak Toba akan lebih diresapi dengan iringan alat musik tradisional seperti gondang hasapi dan gondang sabangunan (Sinaga, 2016:3). Budaya suku Batak akan lebih menarik untuk diperhatikan apabila pengelolaan seluruh aspek tari Sigale-gale dilakukan dengan mempertahankan keaslian pertunjukan seperti dulu bukan merubahnya karena kekuatan budaya berada pada tradisi yang tidak berubah dari zaman dahulu sampai sekarang sehingga wisatawan dapat merasakan suasana kehidupan masyarakat Batak Toba yang asli seperti kembali pada masa lalu (Cheer et al., 2013:8).

Wisata budaya khususnya tari Sigalegale di Desa Tomok berperan penting dalam mendeskripsikan ciri khas suku Batak Toba secara detail mulai dari ulos sebagai kain adat, gondang, garantung, pangora, hasapi dan serune sebagai alat-alat musik Batak Toba, tari Tortor dan rumah Bolon (rumah tradisional Batak Toba). Hal ini sejalan dengan pendapat Hanan et al., (2015:189) bahwa "rumah tradisional berperan penting dalam sejarah masyarakat Batak Toba sebagai ungkapan atas suatu peristiwa, isu kemasyarakatan dan melambangkan kesejahteraan hidup masyarakat Batak Toba". Sementara tari telah menjadi ciri khas dan bagian dari kehidupan manusia yang terus maju dan berkembang selama kehidupan tersebut berlangsung (Khutniah dan Iryanti, 2012:12). Menjaga keutuhan budaya merupakan upaya untuk meningkatkan kesejahteraan hidup masyarakat Batak Toba. Setiap upaya melestarikan budaya menjadi wujud kecintaan terhadap alam dan nilai-nilai kebudayaan yang menunjukkan identitas suatu masyarakat, karena budaya memiliki hubungan yang sangat erat dengan alam (Gullino and Larcher, 2013:391).

\section{LANDASAN TEORI Value}

Galbraith dalam Coombs (2018:6) memaparkan bahwa "nilai adalah upaya untuk menjelaskan tingkatan yang telah ditetapkan menjadi pusat disiplin sejak lahir. Cara yang berbeda untuk mengkonsep nilai, dimana nilai didefinisikan sebagai suatu wawasan yang memiliki batasan dari ilmu ekonomi."Menurut Kluckhohn dalam Syarifuddin (2017:11) "nilai merupakan suatu konsepsi yang secara eksplisit dapat membedakan individu atau kelompok, karena memberi ciri khas baik individu maupun kelompok."

Sedangkan menurut Syarifuddin (2017:11) mendefinisikan bahwa "nilai adalah hal yang dapat membedakan antara manusia dalam masyarakatnya dengan makhluk lain, karena nilai dapat dijadikan sebagai acuan untuk mencapai kehidupan yang lebih berkualitas." Daroeso dalam Kuswarsantyo (2012:19) mengemukakan bahwa: Nilai adalah suatu penghargaan atau kualitas terhadap sesuatu hal yang dapat menjadi dasar penentu tingkah laku seseorang. Sesuatu itu dianggap bernilai bagi seseorang karena sesuatu itu menyenangkan (pleasant), memuaskan (satisfying), menarik (interest), berguna (useful), menguntungkan (profitable), atau merupakan suatu keyakinan (bilief). Berdasarkan keempat definisi nilai yang dipaparkan oleh para ahli, maka dapat ditarik kesimpulan bahwa nilai adalah suatu konsep yang dapat membedakan antara manusia dalam masyarakatnya dengan makhluk lain dan merupakan upaya untuk menjelaskan tingkatan yang telah ditetapkan menjadi pusat disiplin sejak lahir atau menjelaskan kualitas yang dapat menjadi dasar penentu tingkah laku seseorang. 


\section{METODE}

Setiap penelitian menggunakan metode dalam pengerjaannya. Metode penelitian yang digunakan dalam menyelesaikan permasalahan yang menjadi topik penelitian saat ini adalah metode kualitatif bersifat deskriptif. Metode kualitatif adalah teknik mengolah data yang sesuai dengan kriteria penelitian untuk memperoleh data yang berkualitas, guna mendukung kegiatan peneliti melalui data kualitatif yang valid dari beberapa perspektif (Barbour dalam O'Reilly dan Parker, 2015:191).

Metode penelitian ini juga bersifat deskriptif, artinya mengolah data primer (hasil observasi dan wawancara) dan data sekunder (literatur yang berkaitan) secara mendalam untuk mendeskripsikan topik penelitian (Priyanto, dkk. 2018:35). Maka yang dimaksud dengan metode Kualitatif bersifat deskriptif adalah teknik mengolah data primer dan data sekunder untuk mendeskripsikan topik penelitian sehingga memperoleh data kualitatif yang valid.

\section{HASIL DAN PEMBAHASAN Esensi yang Terkandung dari Tari Sigale- gale}

Pertunjukan tari Sigale-gale dimaknai sebagai pertunjukan wisata yang unik karena ada unsur-unsur dan nilai-nilai budaya suku Batak yang berguna untuk menambah wawasan, dimana konsep seni dibuat untuk mempertahankan suatu keyakinan dalam mengantar arwah mendiang yang telah meninggal (suatu upacara adat Batak) dari generasi ke generasi yang berawal dari rasa peduli dan penghiburan terhadap sejarah kerajaan suku Batak terdahulu, ketika anak semata wayang raja meninggal. Suku Batak sangat kental akan kisah kerajaan pada masa lalu. Itulah sebabnya semua orang Batak memiliki marga (nama keluarga) yang berasal dari nama-nama para raja dan keturunannya.

Kisah kerajaan suku Batak melatarbelakangi terbentuknya destinasidestinasi wisata budaya di desa Tomok. Kebudayaan juga turut menggerakkan perekonomian masyarakat karena menjadi sumber pencaharian melalui kegiatankegiatan yang mendukung aktivitas wisata seperti menjadi tour guide, pedagang souvenir, penggiat seni dalam pertunjukan tari Sigale-gale. Mengingat bahwa tari Sigale-gale telah memberikan kontribusi yang besar dibidang pariwisata dan menjadi masterpiece wisata budaya di desa Tomok.

\section{Keadaan Wisata Budaya di Desa Tomok}

Seiring berjalannya waktu, keadaan wisata budaya di desa Tomok saat ini mulai kurang kondusif sehingga perlu ditata kembali. Hal-hal yang membuat keadaan wisata budaya di desa Tomok menjadi kurang kondusif, yaitu kondisi beberapa destinasi wisata budaya di desa Tomok berada di ruang terbuka seperti pertunjukan tari Sigale-gale. Sehingga tidak ada batasan bagi wisatawan yang sedang menyaksikan pertunjukan dengan wisatawan yang baru saja tiba di lokasi destinasi tersebut. Hal ini membuat wisatawan yang baru tiba akan ikut menyaksikan meski sudah dipertengahan acara. Sehingga nilai-nilai budaya tidak tersampaikan dengan utuh dan banyaknya pilihan tempat yang juga menampilkan tari Sigale-gale dengan jarak yang tergolong berdekatan membuat keadaan kurang kondusif (ribut). Karena saat salah satu destinasi Sigale-gale sedang menampilkan pertunjukan, suaranya akan terdengar di tempat lain (tempat yang juga menampilkan tari Sigale-gale).

Keadaan yang kurang kondusif membutuhkan penanganan dan strategi yang tepat. Untuk itu perlu kerja sama antara pihak pengelola destinasi dengan Dinas Pariwisata. Namun, pihak pengelola wisata tari Sigale-gale di desa Tomok masih belum terbuka untuk bekerja sama dengan pihak Dinas Pariwisata dalam hal pengelolaan. Sehingga pihak Dinas Pariwisata mengalami kendala untuk menyalurkan ide-ide dan terbatas dalam mengalokasikan dana perawatan fasilitas-fasilitas wisata yang dibutuhkan oleh pihak pengelola tari Sigalegale. 
Rian Andriani, Erlangga Brahmanto dan Beatrix C. C. Simamora Purba: Value Tari SigaleGale Dalam Meningkatkan Wisata Budaya Di Desa Tomok Kabupaten Samosir

\section{Value Tari Sigale-gale}

Dampak yang bermanfaat dari pendidikan sadar wisata, diharapkan mampu membuat setiap komponen penggerak kepariwisataan sadar akan nilai-nilai budaya yang harus dipertahankan. Khususnya nilainilai (values) yang terkandung dalam pertunjukan tari Sigale-gale. Value merupakan manfaat yang diterima (dirasakan) oleh seseorang setelah menyaksikan suatu peristiwa. Tujuan dari pertunjukan tari Sigale-gale yaitu menyampaikan nilai-nilai yang terkandung di dalamnya. Namun seiring perkembangan zaman, nilai-nilai tersebut sulit tersampaikan karena terdapat perubahan cara dalam menampilkan pertunjukan.Perubahan yang terjadi yaitu, tari Sigale-gale tidak lagi ditampilkan dengan iringan suara alat-alat musik tradisional khas Batak yang dimainkan oleh sekelompok orang, tetapi kini ditampilkan dengan iringan suara dari kaset yang diputar. Pertunjukan Sigale-gale juga tidak lagi diiringi oleh para penari yang lemah gemulai untuk meramaikan suasana pertunjukan.

Perubahan-perubahan yang terjadi membuat wisatawan merasa kurang terhibur, kurang puas dan kurang tertarik untuk memperhatikan pertunjukan hingga selesai. Apabila para wisatawan yang berkunjung ke destinasi Sigale-gale sering merasa kurang terhibur, kurang puas dan kurang tertarik untuk menyaksikan tari Sigale-gale sampai selesai, itu artinya ada masalah yang timbul akibat perubahan yang terjadi dalam pertunjukan tersebut. Jika wisatawan terusmenerus merasakan hal-hal tersebut, maka sebaiknya pengelola kembali menggunakan alat-alat musik tradisional dan manampilkan para penari yang dapat menghidupkan suasana pertunjukan. Kemudian mengkolaborasikan pertunjukan dengan tarian lain (khas Batak) agar pertunjukan semakin menarik minat wisatawan. Karena pertunjukan merupakan suatu atraksi atau elemen utama yang menarik dari suatu destinasi dan merupakan motivator kunci bagi wisatawan. Hal yang serupa dipaparkan seorang ahli bahwa, untuk menimbulkan ketertarikan, rasa senang dan kepuasan pengunjung, pihak pengelola harus memperkuat komponen-komponen dalam pertunjukan, merancang kembali tanpa mengurangi unsur-unsur nilai di dalamnya dan mengelola pertunjukan tersebut dengan profesional (Abdulhaji dan Yusuf, 2016:137).

Mengelola pertunjukan dengan baik dan benar merupakan suatu keuntungan bagi pihak pengelola dan wisatawan. Contoh kongretnya ketika pihak pengelola tari Sigale-gale berkomitmen untuk menampilkan pertunjukan dengan mengenakan pakaian adat Batak Toba (ulos), wisatawan merasa senang karena hal tersebut unik baginya dan merasa tertarik karena alur cerita dalam pertunjukan Sigalegale mengisahkan sejarah kerajaan Suku Batak Toba dan kebudayaannya. Selain itu pemandu tari Sigale-gale juga diwajibkan untuk mengajak wisatawan turut menari bersama, sehingga wisatawan merasa puas karena telah diajarkan manortor (menari). Pihak pengelola juga membuat tarif yang terjangkau untuk menyaksikan tari Sigalegale yaitu, Rp.5000/orang dan Rp.85.000/rombongan. Tarif yang terjangkau secara tidak langsung menjadi suatu keuntungan yang dirasakan oleh wisatawan. Selain menguntungkan, pertunjukan tari Sigale-gale juga berguna menambah wawasan tentang keragaman budaya yang ada di Indonesia. Kebudayaan yang membuat wisatawan merasa yakin terhadap cerita sejarah kerajaan Suku Batak Toba pada zaman dulu.

Cerita sejarah kerajaan Suku Batak Toba dalam pertunjukan tari Sigale-gale merupakan tradisi yang menyiratkan unsur keyakinan. Hal ini sejalan dengan pendapat Sinaga (2016:3) bahwa "Orang Batak Toba, baik secara pribadi maupun kelompok mengakui ada kuasa di luar kuasa manusia". Kesimpulannya, value yang dirasakan oleh para wisatawan setelah menyaksikan pertunjukan tari Sigale-gale yaitu suatu penghargaan atau kualitas terhadap sesuatu 
hal yang dapat menjadi dasar penentu tingkah laku seseorang. Sesuatu itu dianggap bernilai bagi seseorang karena sesuatu itu menyenangkan (pleasant), memuaskan (satisfying), menarik (interest), berguna (useful), Daroeso dalam Kuswarsantyo (2012:19). Dengan demikian dapat disimpulkan bahwa nilai tari Sigale-gale berperan penting dalam mempengaruhi wisatawan untuk mengeksplor lebih dalam lagi tentang budaya suku Batak Toba, dengan mengunjungi destinasi-destinasi wisata budaya lainnya yang ada di desa Tomok, Kabupaten Samosir.

\section{KESIMPULAN}

Penelitian yang bertemakan "Value Tari Sigale-Gale Dalam Meningkatkan Wisata budaya di Desa Tomok, Kabupaten Samosir" menyimpulkan 3 hal utama yaitu:

1. Prosesi tari Sigale-gale sejak dulu hingga kini tidak mengalami perubahan namun cara menampilkannya yang berubah. Awalnya pertunjukan Sigale-gale diiringi alunan suara alat-alat musik yang dimainkan oleh 6 orang. Namun, saat ini pertunjukan tari Sigale-gale hanya ditampilkan dengan iringan suara musik dari kaset yang diputar. Hal tersebut membuat wisatawan tidak tertarik memperhatikan pertunjukan sampai selesai dan menggeser nilai-nilai yang ada di pertunjukan tersebut.

2. Pandangan masyarakat setempat tentang makna tari Sigale-gale yaitu, suatu pertunjukan yang menceritakan tradisi suku Batak Toba pada zaman dulu dan kini menjadi sumber penghasilan masyarakat sekitar. Sementara bagi wisatawan sebagai masyarakat secara umum, tari Sigale-gale menyiratkan makna penghormatan terhadap tradisi yang mulai mengalami pergeseran nilai. Hal tersebut dikarenakan cara manampilkan pertunjukan kurang interaktif dan tidak adanya pemain alat musik tradisional Batak seperti dulu.

3. Nilai tari Sigale-gale perlu dipertahankan dengan mengembalikan cara menampilkan pertunjukan tari Sigale-gale seperti sedia kala yaitu mengiringi pertunjukan dengan alat musik tradisional khas batak dan menghadirkan penari yang handal dalam menarik minat wisatawan untuk ikut manortor (menari).

Saran yang diberikan:

1. Hasil penelitian ini diharapkan mampu menyadarkan pihak pengelola destinasi wisata Sigale-gale di Desa Tomok dan Dinas Pariwisata Kabupaten Samosir untuk membangun hubungan kerja sama yang baik.

2. Potensi wisata Sigale-gale diharapkan dapat menyemangati pengelola Sigalegale dan Dinas Pariwisata Kabupaten Samosir dalam menjaga nilai-nilai budaya yang terkandung di dalamnya.

\section{DAFTAR PUSTAKA}

Abdulhaji S., \& Yusuf I. S. Hi. (2016) 'Pengaruh Atraksi, Aksesibilitas dan Fasilitas Terhadap Citra Objek Wisata Danau Tolire Besar di Kota Ternate', 7(2), pp. 134-148.

Amanah Dita, Hurriyati Ratih, Gaffar Vanessa, A. F. and Ansari, H. D. (2018) 'Foreign Tourist's Attitude To The Elements Of The Developing Of Tourism In Medan, Indonesia', 8, pp. 371-380. doi: 10.5267/j.msl.2018.4.009.

Aprillea Renava, Kusumah, A.H.G., Wirakusuma Reiza Miftah. (2018) Factor Analysis That Forms Expectationof Guest House Guest Experience. Journal of Indonesian Tourism, Hospitality and Recreation 1 (2) $\mathrm{pp}$ 23-30. http://dx.doi.org/10.17509/jithor.v1i2.1 3763.

Badan Pusat Statistik Provinsi Sumatera Utara (2018)

Brahmanto Erlangga (2013) 'Strategi Pengembangan Wisata Gua Pindul Melalui Program Pemberdayaan Masyarakat Sekitar', 4(2), pp. 43-47.

Brahmanto Erlangga (2014) 'Tradisi Rasulan Menjadi Andalan Etnik 
Rian Andriani, Erlangga Brahmanto dan Beatrix C. C. Simamora Purba: Value Tari SigaleGale Dalam Meningkatkan Wisata Budaya Di Desa Tomok Kabupaten Samosir

Tourism Kabupaten Gunung Kidul Yogyakarta', Jurnal Pariwisata, V(2), pp. 69-75.

Cheer Joseph M., Reeves Keir J., Laing

Dinas Pariwisata Kabupaten Samosir, 2018

Jennifer H. (2013) 'Tourism And Traditional

Culture: Land Diving In Vanuatu', Annals Of Tourism Research. Elsevier Ltd, 20(20), pp. 1-21. doi: 10.1016/j.annals.2013.06.005.

Ginting Nurlisa (2016) 'How Self-Efficacy Enhance Heritage Tourism in Medan

Historical Corridor, Indonesia', Procedia Social and Behavioral Sciences. Elsevier B.V., 234, pp. 193-200. doi: 10.1016/j.sbspro.2016.10.234.

Gullino Paola, L. F. (2013) 'Integrity in UNESCO World Heritage Sites. A Comparative Study For Rural Landscapes', Journal of Cultural Heritage. Elsevier Masson SAS, 14(5), pp. 389-395. doi: 10.1016/j.culher.2012.10.005.

Hanan Himasari, Suwardhi Deni, Nurhasanah Tika, B. S. E. (2015) 'Batak Toba Cultural Heritage and Close-range Photogrammetry', 184(August 2014), pp. 187-195. doi: 10.1016/j.sbspro.2015.05.079.

Hanan Himasari (2012) 'Modernization and Cultural Transformation: The Expansion of Traditional Batak Toba House in Huta Siallagan', Procedia Social and Behavioral Sciences. Elsevier B.V., 50(July), pp. 800-811. doi: 10.1016/j.sbspro.2012.08.082.

Hariyanto, O. I. B. (2016) 'Destinasi Wisata Budaya Dan Religi Di Cirebon', Jurnal Wisata Budaya, IV(2), pp. 214222.

Hariyanto, O. I. B. (2017) 'Membangun Karakter Sadar Wisata Masyarakat Di Destinasi Melalui Kearifan Lokal Sunda', Jurnal Pariwisata, IV(1), pp. 33-40.
Hariyanto Oda I. B., Andriani Rian, K. Y. P. (2018) 'Pengembangan Kampung Tulip Sebagai Wisata Edukasi di Bandung', pp. 14-20.

Khutniah Nainul, I. V. E. (2012) 'Upaya Mempertahankan Eksistensi Tari Kridha Jati Di Sanggar Hayu Budaya Kelurahan Pengkol Jepara', 1(1), pp. 9-21.

Pinem Mbina, N. I. (2009) 'Persebaran dan Potensi Objek Wisata di Kota Medan', Jurnal Geografi, 1(1), pp. 57-64.

Priyanto R., Syarifuddin D., \& M. S. (2018) 'Perancangan Model Wisata Edukasi di Objek Wisata Kampung Tulip', Pengabdian Kepada Masyarakat, 1(1), pp. 32-38.

Sagala Patricia L (2017) 'Motivasi Wisatawan Berkunjung ke Daerah Tujuan Wisata Danau Toba, Sumatera Utara', Jurnal Sosiologi, 4, pp. 1-15.

Sigalingging Sarmaida T. R. (2013) 'Struktur Dan Nilai Budaya Batak Toba Dalam Sastra Lisan Huta Silahisabungan', Jurnal Sastra, 2(2).

Sinaga R. H (2016) 'Rekonstruksi Folklor Batak Toba Dalam Bentuk Pertunjukan Tortor Sigale-Gale', pp. 1-10.

Sinaga Rini H (2016) 'Rekonstruksi Folklor Batak Toba Dalam Bentuk Pertunjukan Tortor Sigale-Gale', pp. 1-10.

Suriadi M. Agus (2015) 'Strategies of Cultural Gap Translation in World Herritage - Sites and Living Culture of Indonesia', 21, pp. 93-103.

Syarifuddin Didin (2017) 'Nilai Budaya Batik Tasik Parahiyangan Sebagai Daya Tarik Wisata Jawa Barat', 14, pp. 9-20.

Wardani Mentari Puspa, N. N. A. (2016) 'Kontribusi Pengembangan Pariwisata Danau Toba Melalui Skema BOP (Badan Otorita Pariwisata) Bagi Masyarakat Di Sekitar Danau Toba', (December). 